\title{
Magnetic resonance imaging in the diagnosis of spinal cord diseases
}

\author{
F AICHNER, W POEWE, W ROGALSKY, K WALLNÖFER, J WILLEIT, \\ F GERSTENBRAND
}

From the Department of Neurology, University of Innsbruck, Austria, Radiological Institute K Wallnöfer, Munich and Siemens AG, Medical Engineering Group, Erlangen, Federal Republic of Germany

SUMMARY Experience with magnetic resonance imaging in 22 patients with diseases of the spinal cord is reported. Important additional diagnostic information as compared to conventionai neuroradiological techniques (myelography, spinal CT) was gained especially in cases of hydrosyringomyelia, intraspinal tumour and multiple sclerosis. It is suggested that magnetic resonance imaging may become the method of choice in the diagnosis of structural spinal cord diseases.

Diagnosis of diseases of the spinal cord is based on clinical findings and on the results of a variety of complementary examinations. The latter currently include CSF analysis, somatosensory evoked potentials, myelography, myeloscintigraphy, spinal computed tomography (CT) and spinal digitalised subtraction angiography. Despite this array of sophisticated diagnostic techniques the differential diagnosis of spinal cord lesions cannot be clarified in many instances, or is only established at operation, or on post mortem examination.

With the advent of nuclear magnetic resonance imaging (MRI), tomograms of soft tissue structures have become possible..$^{1-4}$ The ability to visualise the spinal cord in vivo makes MRI of special value for the diagnosis of spinal cord diseases. ${ }^{5-8}$ The exact craniocaudal extent of a medullary lesion can be determined using sagittal and coronary scans. The precise localisation of a spinal cord lesion requires imaging of very high resolution. This can be achieved by MRI by using zooming techniques, surface coils and reduction of slice thickness to a few millimeters without any loss of optimal image quality. Thus MRI has become the first non-invasive procedure not only to determine the exact localisation and expansion of a pathological medullary con-

Address for reprint requests: Doz Dr F Aichner, Univ-Klinik für Neurologie, Anichstraße 35, A-6020 Innsbruck, Austria

Received 13 September 1984 and in revised form 14 February 1985.

Accepted 16 February 1985 dition, but also to distinguish between solid and cystic areas of spinal cord tumours. Multiple sclerosis plaques of the spinal cord have for the first time been demonstrated in vivo by MRI.

This study presents the current potential and limitations of MRI in the differential diagnosis of spinal cord diseases, and delineates some guidelines for the indication and performance of spinal MRI examination.

\section{Patients and methods}

Between August 1983 and July 1984 the authors have examined 22 selected patients with various spinal cord diseases by MRI (table). All patients had a complete neurological and neuroradiological examination before performing MRI of the spinal cord. Ten patients were examined with a PICKER 0.15 tesla system and twelve patients by SIEMENS 0.35 and 0.5 tesla systems respectively. The head coil was employed for imaging of the cervical cord, and the body coil for the rest of the cord. Zooming and surface coil were also available. In all cases the inversion recovery technique (IR) and the spin-echotechnique (SE) were used with different recovery times (TR from 400 to $2000 \mathrm{~ms}$ ) and different echo times (TE

\section{Table Diagnosis in 22 patients}

\begin{tabular}{ll}
\hline - multiple sclerosis & 4 \\
- myelitis of unknown origin & 2 \\
Z hydrosyringomyelia & 4 \\
- traumatic transversale-syndrome with posttraumatic & 2 \\
- syringomyelia & 1 \\
Z exinal cord tumour & 6 \\
Z tumour of the cauda equina & 1 \\
- cervical myelopathy & 1 \\
Z amyotrophic lateral sclerosis & 1 \\
\hline
\end{tabular}


from 23 to $86 \mathrm{~ms}$ ). Sagittal and axial slicing was preferred; coronary scans of the spinal cord were judged less informative owing to the bending of the cord.

\section{Case reports}

Some characteristic case reports with representative MR images will be given in detail. Cases 3 and 6 have been mentioned in former publications. ${ }^{59}$

Case 1, male aged 21 yr Following a skiing accident with a subluxating fracture of the fourth thoracic vertebral body the patient developed a complete transverse cord syndrome distal to $\mathrm{D} 4$. Approximately 4 months after the accident the patient experienced progressive weakness of both arms and hands. Neurological examination at this time revealed an incomplete transverse syndrome caudal to $C 7$ which became complete at the level of D 4 . The CT findings confirmed the presence of hydrosyringomyelia extending from C 4 caudally to $D 10$ (fig 1a-c). The corresponding MR images in the sagittal and axial planes are depicted in fig 2 a-d.

Case 2, male aged $42 \mathrm{yr}$ This patient had suffered from a multifocal neurological disease for about 13 years, dominated by a spastic quadriparesis. He had been diagnosed as having clinically definite multiple sclerosis according to the criteria of McDonald and Halliday. ${ }^{10} \mathrm{MRI}$ examination of the spinal cord ( 0.15 tesla, TR $2000 \mathrm{~ms}$, TE $43 \mathrm{~ms})$ revealed multiple areas of altered signal intensity within the thoracic cord (fig $3 a, b$ ).

Case 3, male aged $26 y r$ This patient had a progressive transverse syndrome from the level of $\mathrm{C} 3$ for more than 2 years. Spinal CT had shown a grossly distended spinal cord at the level of the atlas extending into the foramen magnum suggestive of an intramedullary tumour. The MRI findings confirmed the diagnosis (fig $4 \mathrm{a}, \mathrm{b}$ ).

Case 4, female aged 40 yr At the age of 37 years the patient had developed a progressive paraparesis with a sensory level at D 12. Descending myelography revealed an incomplete blockage of contrast material at the level of D 8 suggestive of an extramedullary expanding lesion. At laminectomy an extramedullary arteriovenous malformation was found and was partly removed through an extended laminectomy from $\mathrm{D} 7$ to $\mathrm{L} 1$. The diagnosis was confirmed histologically. Three months after the operation, severe burning pains in the L 4 and $L 5$ dermatomes of both legs recurred, and the neurological findings now were suggestive of a lesion of the cauda equina at the level of $L$ 4. Spinal CT with intrathecal contrast enhancement failed to visualise the intraspinal structures caudal to D 9. An exploratory laminectomy at the level of L 4 and $L 5$ revealed an epidural tumour which was excised in toto. Histologically the tumour was identified as an endotheliomatous meningeoma. The postoperative MRI findings in this patient are depicted in fig $5 \mathrm{a}, \mathrm{b}$.

Case 5, female aged $68 \mathrm{yr}$ Two years before admission the patient experienced pain in the left gluteal region and weakness of plantar flexion of the right foot. During the following months there was increasing weakness of plantar and dorsal movement of both feet; gluteal muscles became atrophic on the right and an atonic bladder disturbance developed. Neurological evaluation in 1984 revealed a cauda equina syndrome involving the roots of $L 5$ to $S 5$, with right-sided emphasis. Lumbar CSF had a grossly raised protein content of above $15 \mathrm{~g} / \mathrm{l}$. An expanding lesion compressing the cauda equina was suspected. The diagnosis was confirmed by spinal CT and MRI (fig 6a, c). Surgical exploration at laminectomy from D 11 to $\mathrm{L} 3$ disclosed an intradural, extramedullary tumour which was excised and histologically identified as a myxopapillary ependymoma.

Case 6, female aged $44 \mathrm{yr}$ The patient was known to suffer from von Recklinghausen's neurofibromatosis and had developed a Brown-Sequard syndrome at the level of $C 3$. Radiographs of the cervical spine and spinal CT with intrathecal contrast enhancement revealed a neurinoma of the $C 3$ root on the right. MRI of the cervical spine with sagittal and axial sections disclosed the full extent of the tumour. (fig 7a, b).

Case 7, female aged $46 \mathrm{yr}$ The patient was admitted with the signs and symptoms of a spinal cord lesion at D 10 that had progressively worsened over the last six months. Spinal CT findings suggested an extradural lesion between D 7 and D 9; descending myelography showed partial arrest of contrast material at D 7. MRI of the spinal cord revealed an intraspinal area of increased signal intensity between $D$ 7 and D 8 (fig 8). Surgical exploration of the spinal canal at D 7/D 8 disclosed a meningioma 3 to $2 \mathrm{~cm}$ in diameter compressing the cord from the left.

\section{Results}

With respect to the diagnostic entities listed in the table MRI examination of the spinal cord revealed the following. Four patients had multiple sclerosis, defined by clinical and CSF findings. According to the diagnostic criteria of McDonald and Halliday, one case was classified as definite and three cases were classified as progressive probable multiple sclerosis. In all four cases MRI revealed areas of altered proton signal intensity believed to be characteristic of multiple sclerosis plaques. In two cases such changes were only seen in the cervical and thoracic segments of the spinal cord. In the two other cases, MRI of the spinal cord appeared to be normal. MRI of the brain, however, showed periventricular and brain stem plaques in both patients.

Two patients were suspected of having myelitis of unknown origin on the basis of clinical and CSF findings. In both descending myelography and spinal CT with intrathecal contrast enhancement was normal, as was spinal MRI. Four patients of the group had clinical signs and symptoms of hydrosyringomyelia. Neuroradiological confirmation of that diagnosis was obtained by myelography and spinal CT in two cases, but in the other two such examinations were negative. MRI revealed intramedullary cysts in all four cases. In two further cases the development of posttraumatic hydrosyringomyelia was suspected on clinical grounds and was confirmed 

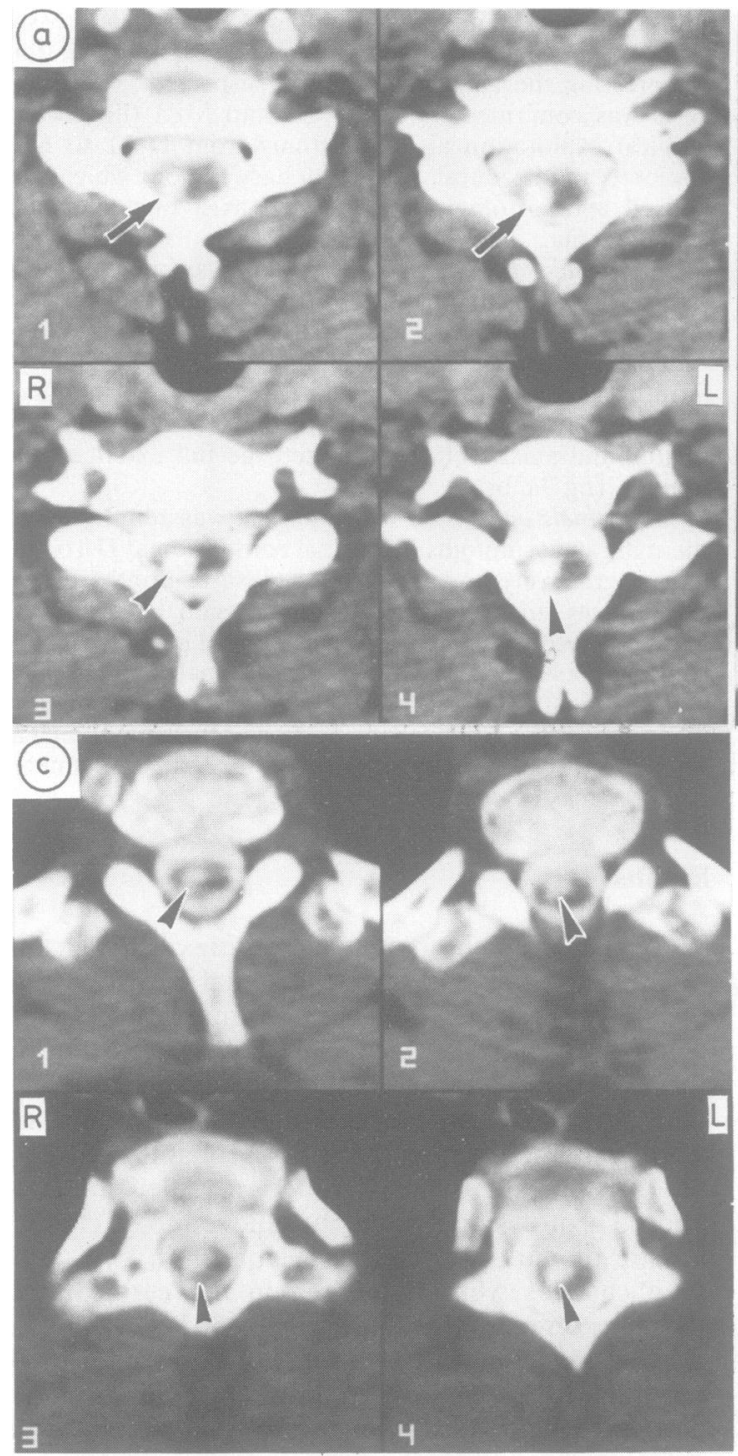

by $\mathrm{CT}$ in one of them. MRI showed a typical cystic spinal cord lesions in both.

Eight patients had been admitted because of clinical symptoms of an intraspinal space occupying lesion (table), with subsequent confirmation by conventional neuroradiological techniques (myelography, CT). In all cases the exact localisation and extension of the neoplasms was visualised by MRI.

In one case of myelopathy due to cervical spondylosis, MRI revealed compression of the cervical spinal cord by osteophytes in a similar manner to spinal CT. One case of amyotrophic lateral sclerosis did not show any abnormality with MRI

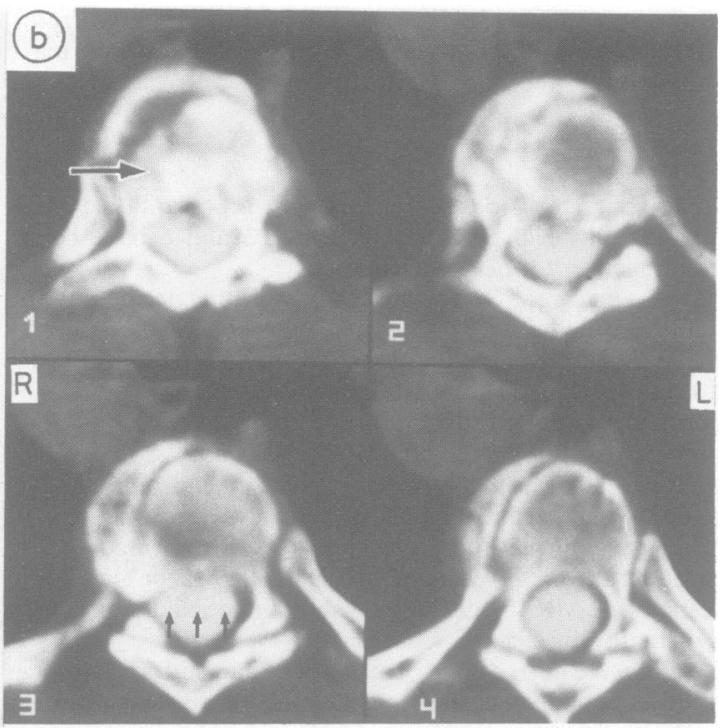

Fig 1 Post-traumatic hydrosyringomyelia, CT scans of case 1. (a) after intrathecal contrast enhancement intramedullary contrast filled syrinx cavity (arrows) is visible at the level of $C 7$. (b) at the level of $D 4$ (fracture) the contrast-filled cavity seems to occupy all of the spinal canal; no medullary tissue visible. (c) at D 7 a similar configuration of the syrinx cavity as seen at $C 7$ is evident.

\section{Discussion}

The results of this study demonstrate important implications, especially with respect to such entities as multiple sclerosis, intramedullary cystic and neoplastic changes as well as extramedullary expanding lesions.

Diagnosis of spinal cord involvement in multiple sclerosis currently is based on clinical, CSF and electrophysiological findings. Frequently such a diagnosis can only be made with some degree of probability. Direct visualisation of multiple sclerosis plaques would solve many diagnostic problems, but for 

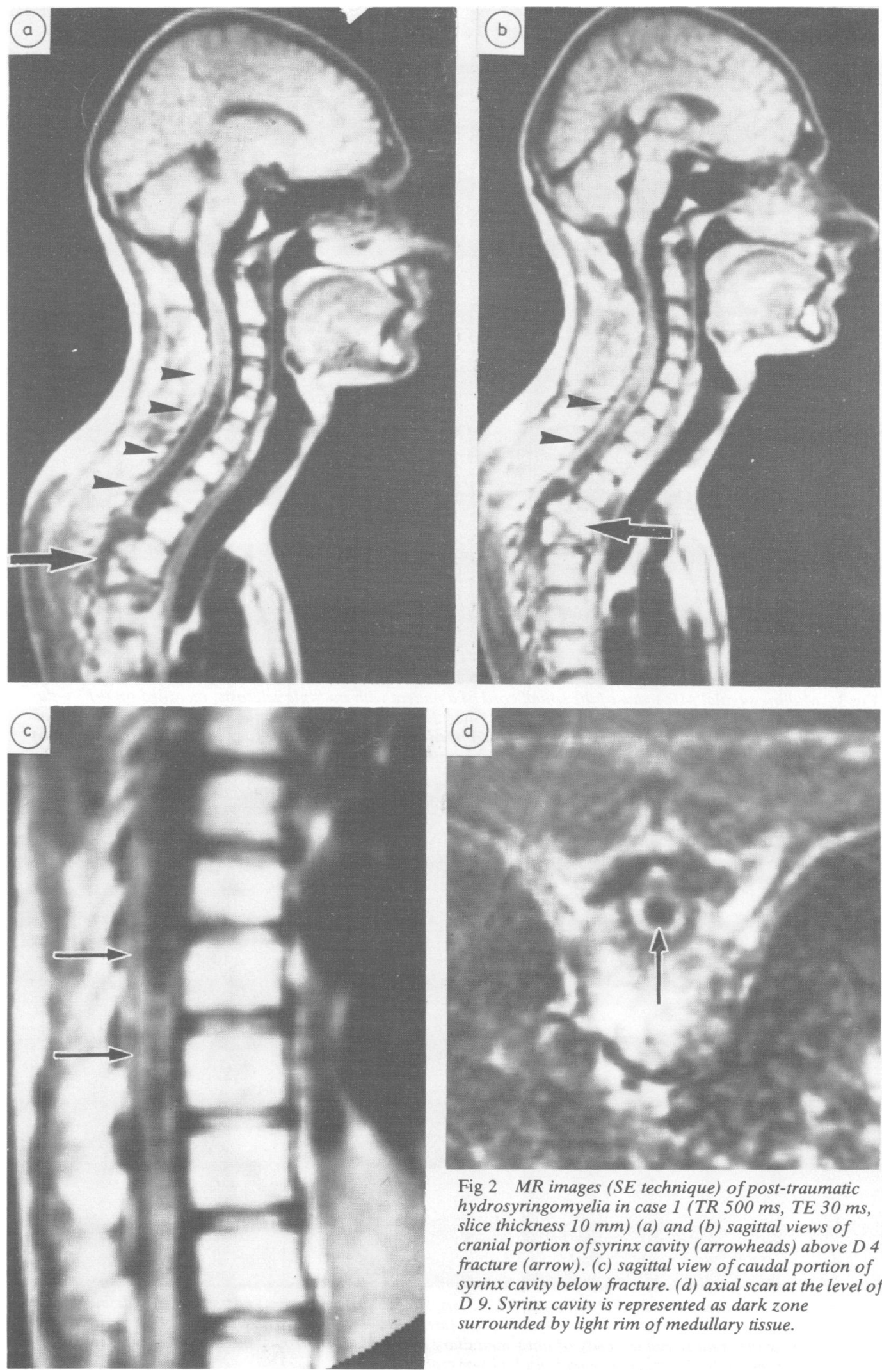

Fig $2 M R$ images (SE technique) of post-traumatic hydrosyringomyelia in case 1 (TR $500 \mathrm{~ms}$, TE $30 \mathrm{~ms}$, slice thickness $10 \mathrm{~mm}$ ) (a) and (b) sagittal views of cranial portion of syrinx cavity (arrowheads) above D 4 fracture (arrow). (c) sagittal view of caudal portion of syrinx cavity below fracture. (d) axial scan at the level of $D$ 9. Syrinx cavity is represented as dark zone surrounded by light rim of medullary tissue. 

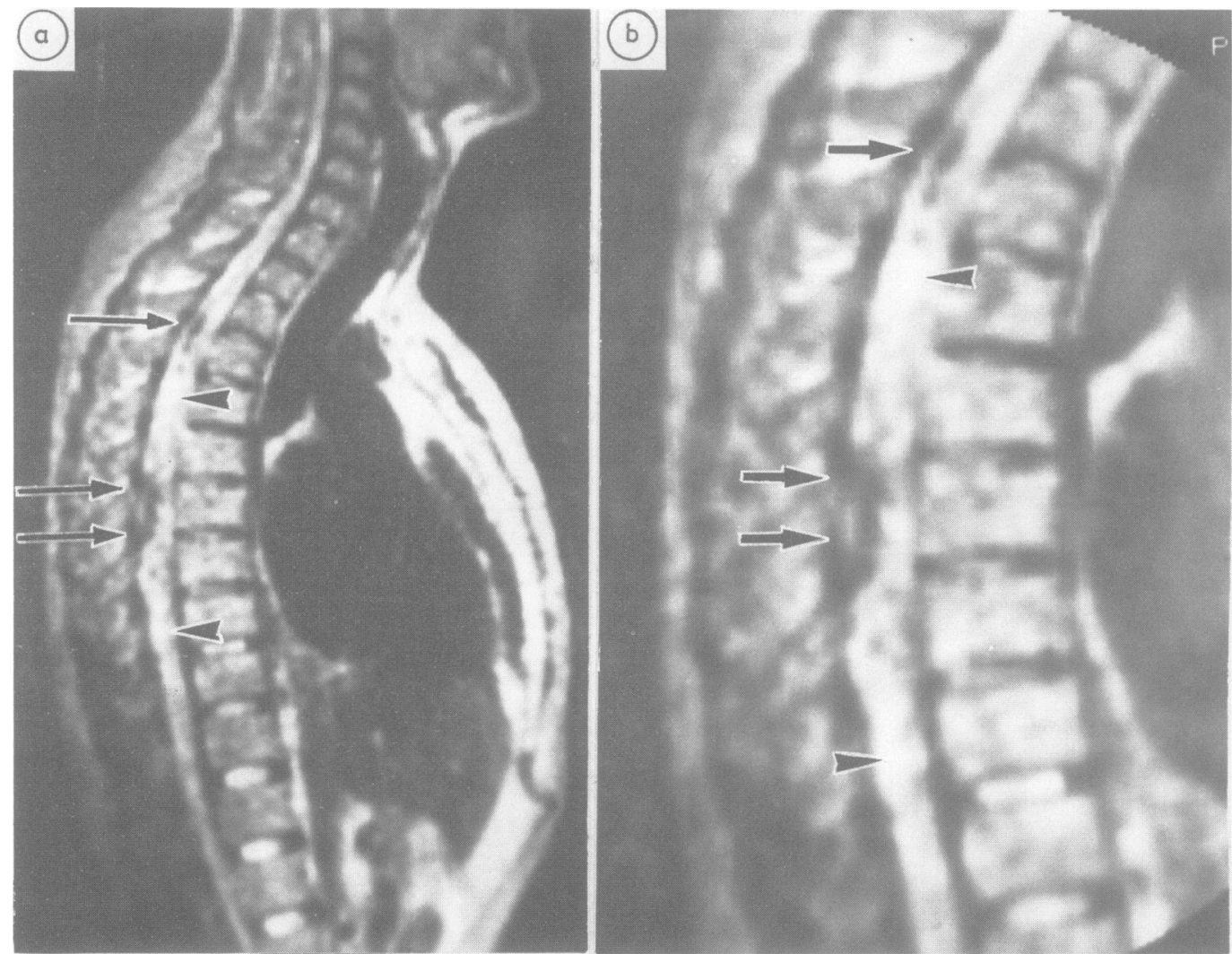

Fig 3 Midline sagittal MR scans of the spinal cord of a patient with multiple sclerosis, recorded on $0 \cdot 15$ tesla system using SE technique (TR $600 \mathrm{~ms}$, TE $45 \mathrm{~ms}$, slice thickness $10 \mathrm{~mm}$ ). (a) multiple areas of altered signal intensity in the thoracic portion of the spinal cord, comprising both areas of low (dark zones $=$ arrows) and of high (light zones = arrowheads) signal intensity. (b) magnified view of (a).
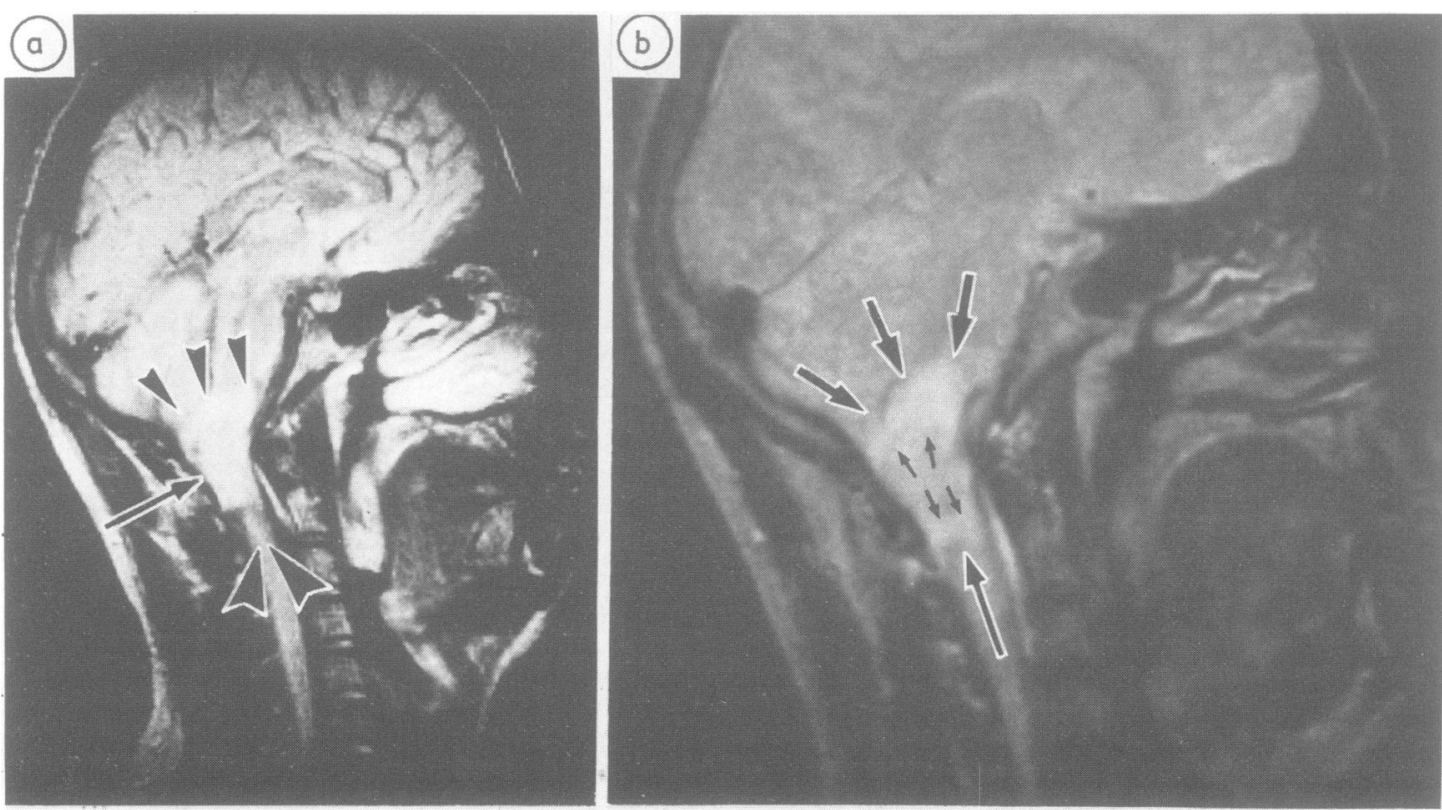

Fig 4 (a) Midline sagittal SE scan (TR $1600 \mathrm{~ms}$, TE $43 \mathrm{~ms}$, slice thickness $10 \mathrm{~mm}$ ) of patient 3. Ill defined area of increased signal intensity is seen at craniocervical junction (arrowheads). (b) SE scan of same region as in (a) with longer TE (86 ms). Note different signal intensity of intra-medullary tumour (short arrows) as compared to perifocal zone (long arrows), corresponding to perifocal oedema found intraoperatively. 


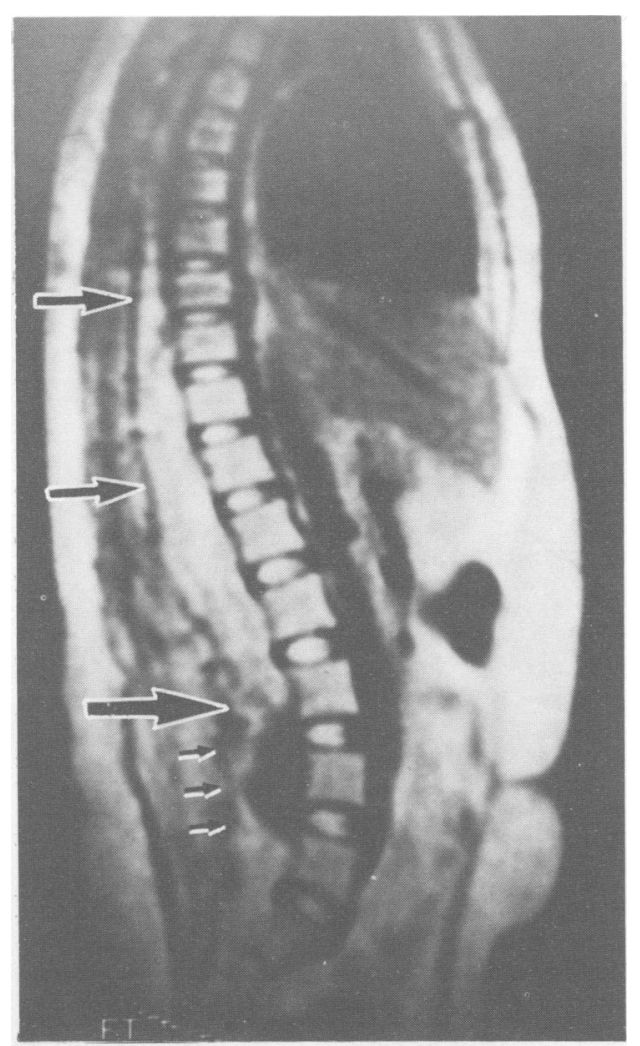

Fig 5 Sagittal SE image of spinal cord in patient 4 (TR $600 \mathrm{~ms}$, TE $43 \mathrm{~ms}$, slice thickness $10 \mathrm{~mm}$ ). Note massive widening of spinal canal caudal to $D 9$ due to medullary tumour (by history a partially removed spinal hemangioma). Caudal to L 4 (big arrow) area of low signal intensity corresponding to resection cavity of epidural meningeoma is visible (small arrows).

the spinal cord this has only been possible in two cases in the literature using CT. ${ }^{112}$ MRI has proved to be a very sensitive technique for detection of intracranial multiple sclerosis plaques..$^{41314}$ There is a prevailing view in the literature that this might not be true for the spinal cord, owing to problems of discrimination between grey and white matter. ${ }^{8}{ }^{15}$ In our cases, multiple sclerosis plaques of the spinal cord appeared as large and multiple changes sharply demarcated and sometimes confluent ("kissing plaques"). These changes sometimes comprised both areas of low and of high signal intensity (see case 2, fig $3 a, b)$. Whether such different alterations in signal intensity of multiple sclerosis plaques correspond in some way to the histochemical grading of plaques described by Seitelberger ${ }^{1617}$ remains speculative, as long as a comparison with pathological data is not possible. It seems that with the use of zooming techniques or surface coils MRI may become equally sensitive for the detection of multiple sclerosis plaques in the spinal cord as for those in the brain. There may also be the possibility of following the natural history, and behaviour in relation to therapy, of spinal cord plaques by MRI.

Myelography and spinal CT are the only neuroradiologic methods currently available to confirm the clinical diagnosis of hydrosyringomyelia. $^{18}$ Even with high resolution contrast enhanced CT about $20 \%$ of medullary syrinx cavities are not detected. ${ }^{19}$ In our case material only three of six patients with clinical signs of hydrosyringomyelia did show corresponding changes in spinal CT. Sagittal MR images clearly revealed tubular CSF-containing central cavities within the spinal cord with low proton signal intensity in all six patients. Optimal visualisation of large portions of the spinal cord is possible with sagittal slices. This can only be achieved by exact positioning of the patient which may be difficult in patients with spinal deformity. Additional localising information may be obtained from coronary and axial sections. ${ }^{592021}$ In MRI of the spinal cord the SE technique is superior to the IR technique. In our series, optimal contrast between syrinx cavity and medullary tissue was provided by using TR values of around $1600 \mathrm{~ms}$, and TE values of around $34 \mathrm{~ms}$. Higher TR and TE values led to increased CSF intensity making the contrast between cavity and cord less sharp.

A communication between syrinx and subarachnoid space as well as associated abnormalities of the posterior fossa and craniocervical junction was seen by MRI in our patients. In the same way, posttraumatic hydrosyringomyelia was identified by MRI. ${ }^{22}$ According to our observations MRI will be the method of first choice for the diagnosis of hydrosyringomyelia.

In all eight patients of our series with intraspinal tumours the diagnosis had been established by clinical and neuroradiological findings before MRI was performed. ${ }^{23-25}$ Nevertheless, MRI yielded important additional information. Localisation of the tumour became more exact by simultaneous visualisation of the cranial and caudal borders by MRI. With the use of MRI with contrast agents even more specific differentiation between various spinal cord mass lesions may become possible. ${ }^{26}$ After a lesion has been identified in MRI, changes in pulse sequence, TE, and TR may lead to optimal distinction between the tumour and surrounding oedema (see case 3 of our series). ${ }^{6}$ In general sagittal scans yield sufficient diagnostic information. In case 7 of this series, the meningioma found at operation produced a MR image on sagittal scanning that was not clearly distinguishable from that of an intramedullary lesion 

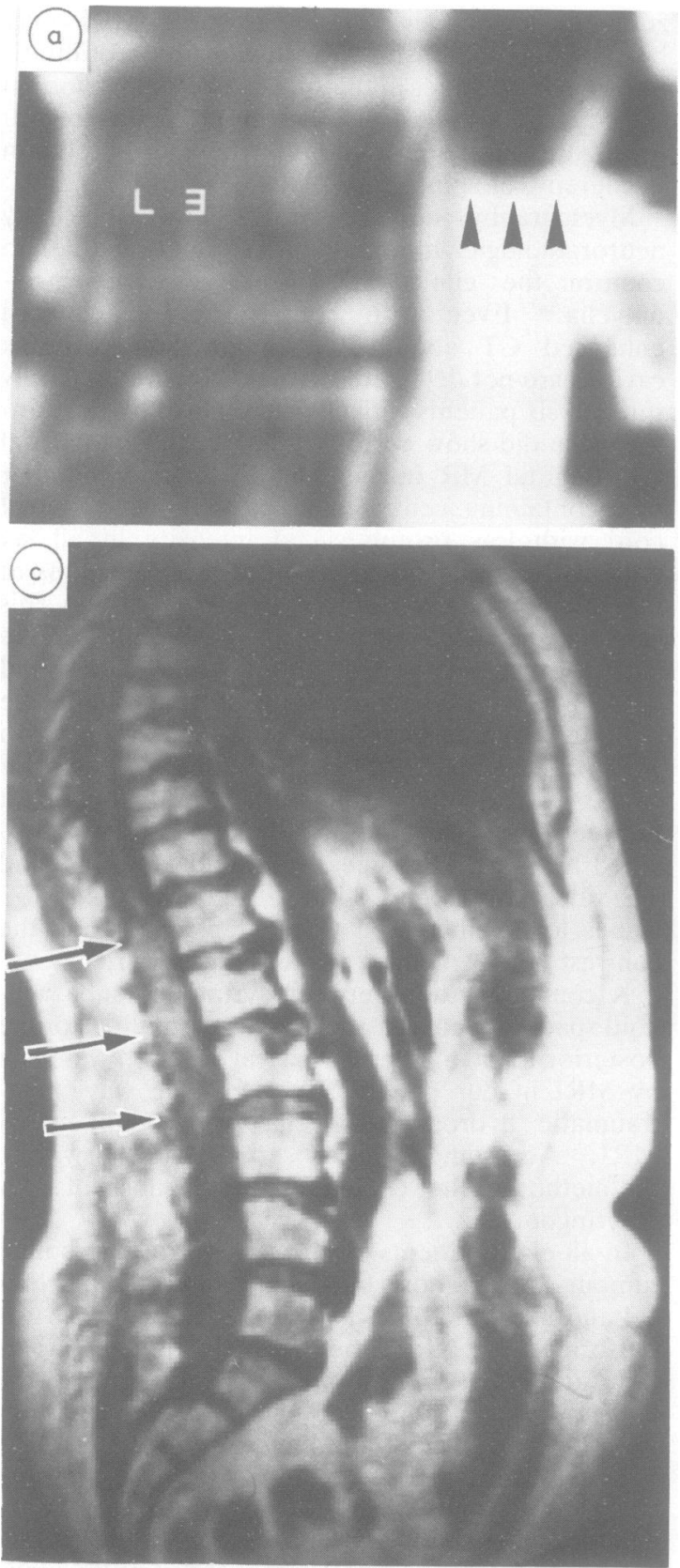

(see fig 8). Additional coronal or transverse scans might have added to the pre-operative information in this case.

At present MRI is highly sensitive in detecting intraspinal neoplasms. The specificity of MRI findings with regard to different types of tumours

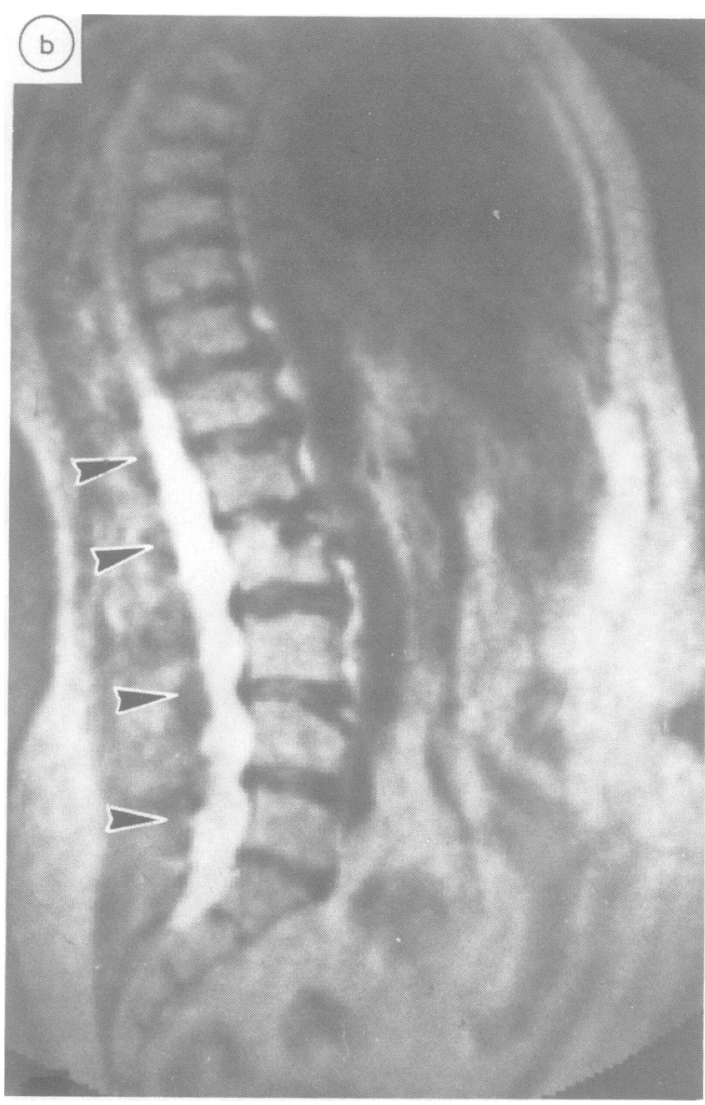

Fig 6 Ependymoma of cauda equina in patient 5. (a) sagittal reformatting of spinal CT scans after intrathecal contrast enhancement. Note concavely shaped arrest of contrast material at the level of $L 3$ corresponding to ependymoma found during operation. (b) midline sagittal $S E$ scan of spinal canal in the same patient (TR $600 \mathrm{~ms}$, $T E 30 \mathrm{~ms}$, slice thickness $10 \mathrm{~mm}$ ). Note intraspinal area of increased signal intensity extending from $D 12$ to lumbosacral junction (arrowheads). (c) same section as in (b) with increased TR $(2000 \mathrm{~ms})$ and TE $(45 \mathrm{~ms})$. Area of increased signal intensity (arrows) is restricted to the length between upper border of $D 12$ and lower border of $L 2$, exactly corresponding to extension of ependymoma found during surgical excision. Area of increased signal intensity caudal to $L 2$ as depicted in (b) is no known correlate and probably reflects oedema of cauda equina and/or engorged epidural veins or is due to massively increased protein content of lumbar CSF $(15 \mathrm{~g} / \mathrm{l}$ in this patient).

needs to be increased by further studies. Application of the surface coil to yield images and ${ }^{31} \mathrm{P}$ spectra of tumour simultaneously is a further step toward increased diagnostic specificity. ${ }^{27}$

From our experience several technical considerations are of special importance for optimal MRI of 

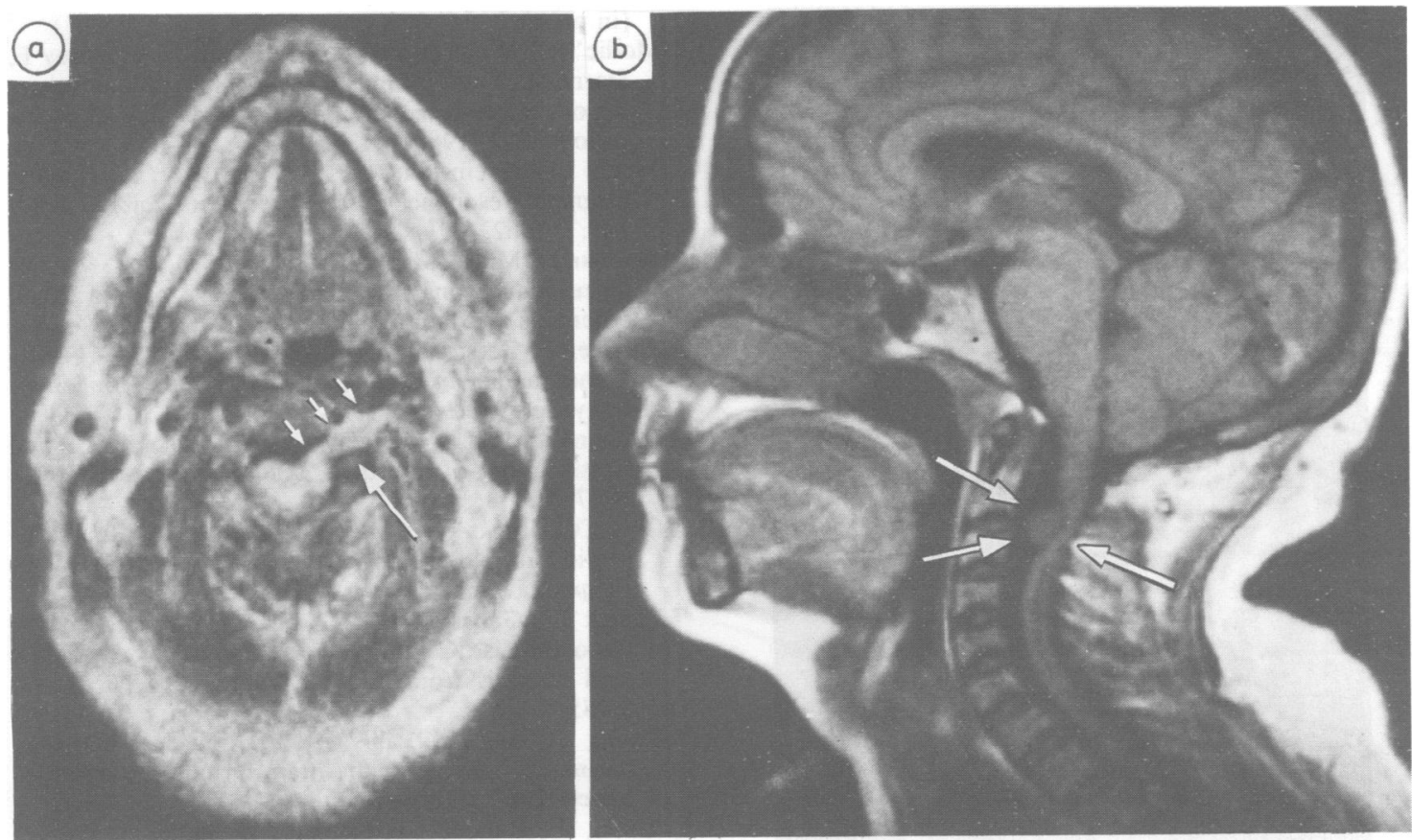

Fig $7 M R$ images of neurinoma of C 3 in patient 6. (a) midline sagittal SE scan (TR 1600 ms, TE 30 ms, slice thickness $6 \mathrm{~mm}$ ) reveals extramedullary tumour with dorsal displacement of the cord (arrows). Signal intensity of tumour is similar to that of the cord. (b) axial scan at the level of $C 3$ shows extension of neurinoma along $C 3$ root on the right.

the spinal cord: (1) the SE technique seems to be superior to IR techniques in yielding optimal contrast. SE images with short TR (300-600 ms) and TE $(30 \mathrm{~ms})$ provide the best signal-to-noise ratio, thereby allowing for the highest contrast differentiation between CSF and spinal cord. With larger TE values the differences in signal-intensity between various soft tissue structures become more pronounced. A selective enhancement of signal intensity of CSF may be achieved by increasing TR and TE $($ TR $=1500-2500 \mathrm{~ms}$, TE up to $200 \mathrm{~ms})$. (2) One of the problems currently limiting the diagnostic yield of MR images of the spinal cord is the relative thickness of sections in relation to the size of the organ examined. Lesions sized less than $1 \mathrm{~cm}$ may thus be missed. On the other hand, very thin sections may cause the same problem by partial volume effects. In our material slice thickness was $1.0 \mathrm{~cm}$ and $0.6 \mathrm{~cm}$. (3) Best visualisation of the spinal cord was obtained by sagittal scans, which implies the need for exact positioning of the patient. (4) Zooming is required to receive axial scans of sufficient resolution. (5) Due to an improved signal-to-noise ratio for structures close to the body surface. A surface coil can be expected further to improve MRI resolution of the spinal cord. ${ }^{27} 28$

At present MRI of the spinal cord appears to be a superior diagnostic approach for several reasons. MRI constitutes the first non-invasive method to give high resolution in vivo images of the spinal cord without any known biological hazard for the patient. Among the major diagnostic advantages is the possibility of visualising spinal cord tumours in their complete cranio-caudal extension, to differentiate between cystic and solid tumour areas as well as between tumour and surrounding oedema. Furthermore multiple sclerosis plaques of the spinal cord appear to be readily detectable by MRI. The major shortcomings of MRI are the high costs of acquisition and maintenance of MR systems and the limitations in examining critically ill patients. From the diagnostic point of view there is still a lack of histological specificity of MR findings, with poor differentiation between grey and white matter of the spinal cord and only limited resolution of surrounding vertebra. 


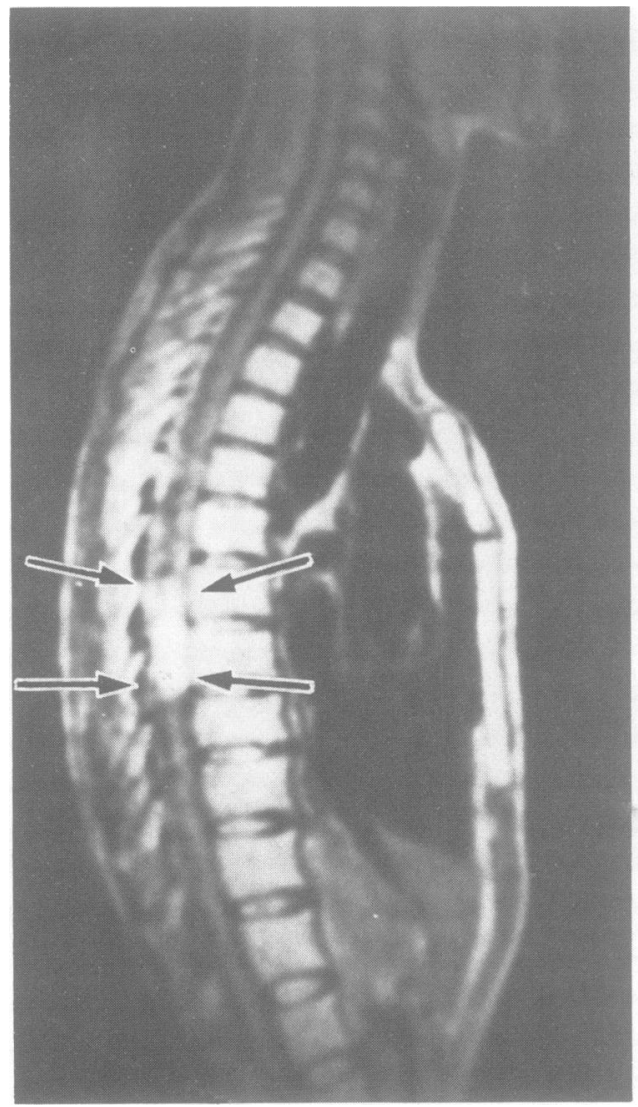

Fig 8 Midline sagittal SE scan of spinal cord in patient 7. (TR $1500 \mathrm{~ms}, T E 45 \mathrm{~ms}$, slice thickness $10 \mathrm{~mm}$ ). Note intraspinal area of increased signal intensity with sharply defined borders at the level of $D 7$ and $D 8$ (arrows), appearing inseparable from the spinal cord.

\section{References}

1 Young SW. Nuclear Magnetic Resonance Imaging. Basic Principles. New York: Raven Press, 1984.

${ }^{2}$ Roth K. NMR-Tomographic und-Spektroskopie in der Medizin. Heidelberg: Springer, 1984.

${ }^{3}$ Young IR, Burl M, Clarke GJ, et al. Magnetic resonance properties of hydrogen: imaging the posterior fossa. AJNR 1981;24:487-93.

${ }^{4}$ Aichner F, Gerstenbrand F, Grcevic N, Mayr U, Noever $\mathrm{K}$, Reuther G. Identification of various pathological conditions of the CNS by nuclear magnetic resonance (NMR) imaging. In: Gerstenbrand F, Grcevic N, Aichner F, eds. Neuroimaging. Stuttgart: Gustav Fischer Verlag, 1985.

s Aichner F, Willeit J, Birbamer G, Mayr U, Gerstenbrand F. Die Kernspintomographie bei Prozessen im Bereiche des Foramen occipitale magnum. Akt Neurol (in press).

- Modic MT, Weinstein MA, Pavlicek W, Baimphrev F, Starnes D, Duchesnan PM. Magnetic resonance imaging of the cervical spine: technical and clinical observations. AJR 1983;141:1129-36.

${ }^{7}$ Modic MT, Weinstein MA, Pavlicec W, et al. Nuclear magnetic resonance of the spine. Radiology 1983; 148: 757-62.

${ }^{8}$ Norman D, Mills CM, Brant-Zawadzki M, et al. Magnetic resonance imaging of the spinal cord and canal: potentials and limitations. $A J R$ 1983;141:1147-52.

' Aichner F, Gerstenbrand G, Huk W, Pallua A. NMRTomographie in der Diagnostik der Syringohydromyelie. Nervenarzt 1984;55:324-7.

${ }^{10}$ McDonald WI, Halliday AM. Diagnosis and classification of multiple sclerosis. $\mathrm{Br}$ Med Bull 1977;33:4-8.

"Coin CG, Hucks-Follis A. Cervical computed tomography in multiple sclerosis with spinal cord involvement. J Comput Assist Tomogr 1979;3:431-22.

${ }^{12}$ Latack JL, Gabrielsen TO, Knake JE, Gebarski ST.S, Dorovini-Zis K. Computed Tomography of spinal cord necrosis from multiple sclerosis. AJNR 1984; 5:485-7.

13 Young IR, Hall AS, Pallis CA, et al. Nuclear magnetic resonance imaging of the brain in multiple sclerosis. Lancet 1981;2:1063-6.

14 Young IR, Randell CP, Kaplan PW, James A, Bydder GM, Steiner RE. Nuclear magnetic resonance (NMR) imaging in white matter disease of the brain using spin-echo sequences. J Comp Assist Tomogr 1983; 7:290-4.

15 Han JS, Kaufman B, El Yousef EL, Benson JE, et al NMR Imaging of the Spine. AJNR 1983;4:1151-9.

${ }^{16}$ Seitelberger F. Histochemistry of demyelinating diseases proper, including allergic encephalomyelitis and Pelizaeus-Merzbacher's disease. In: Arnold E, ed. Modern Scientific Aspects of Neurology. London, 1965:146-87.

${ }^{17}$ Lumsden CE. The neuropathology of multiple sclerosis. In: Vinken PJ, Bruyn GW, eds. Handbook of Clinical Neurology. Amsterdam: North-Holland Publishing Group, 1970: Vol. IX: 217-309.

18 Aubin ML, Vignuad J, Jardin C, Bar D. Computed tomography in 75 clinical cases of syringomyelia. AJNR 1981;2:199-204.

${ }^{19}$ Sotaniemi KA, Pythinen J, Myllylä VV. Computed tomography in the diagnosis of syringomyelia. Acta Neurol Scand 1983;68:121-7.

${ }^{20}$ De La Paz RL, Brady TJ, Buonanno FS, et al. Nuclear magnetic resonance (NMR) imaging of Arnold-Chiari type I malformation with hydromyelia. J Comp Assist Tomogr 1983; 7:126-9.

${ }^{21}$ Yeates A, Brant-Zawadzki M, Norman D, Kaufman L, et al. Nuclear magnetic resonance imaging of syringomyelia. AJNR 1983;4:234-7.

${ }^{22}$ Shannon N, Symon L, Logue V, et al. Clinical features, investigation, treatment of post-traumatic syringomyelia. J Neurol Neurosurg Psychiatry 1981;44:3542.

${ }^{23}$ Marc JA, Schechter MM. Radiological diagnosis of mass lesions within and adjacent to the foramen magnum. 
Radiology 1975;114:351-65.

${ }^{24}$ Nakagawa H, Huang YP, Malis LI, Wolf BS. Comuted tomography of intraspinal and paraspinal neoplasm. $J$ Comput Assist Tomogr 1977;1:377-90.

${ }^{25}$ Nittner $K$. Spinal meningeomas, neurinomas and neurofibromas and hourglass tumours. In: Vinken PJ, Bruyn GW, eds. Handbook of Clinical Neurology. Amsterdam: North-Holland Publishing Company, 1976: Vol. 20:177-322.
${ }^{26}$ Weinmann HJ, Brasch RC, Press WR, Wesbey GE. Characteristics of Gadolinium-DPTA Complex: A potential NMR Contrast Agent. AJR 1984;142:619 24.

${ }^{27}$ Oppelt A. Neue Anwendungen und bessere Bildergebnisse: Trends und Perspektiven in der Kernspintomographie. Electromed 1984;52:56-65.

${ }^{28}$ Axel L. Surface coil magnetic resonance imaging. $J$ Comp Assist Tomogr 1984;8:381-4. 